\title{
Navigation and Indexical Thought
}

\section{Andreas Stokke ${ }^{1}$}

Received: 22 July 2019 / Accepted: 6 April 2020 / Published online: 4 May 2020

(c) The Author(s) 2020

\begin{abstract}
This paper argues for a moderate form of essentialism about indexical thought (also known as de se, first-person, or egocentric thought). According to this moderate essentialism, there is a significant category of intentional action that necessarily involves indexical thought. This category of action is navigation, that is, intentionally moving from one location to another by using public information about the world such as a map or a set of directions. It is shown that anti-essentialists face a challenge in accounting for this kind of action without accepting the involvement of indexical thought or something equivalent. The conclusion that navigation necessarily requires indexical thought is neutral on the strong essentialist claim that there is a special class of indexical propositional attitudes that mandate rejecting standard theories of propositional attitudes. The conclusion is also neutral on the strong essentialist claim that any kind of intentional action necessarily requires indexical thought.
\end{abstract}

\section{Introduction}

A familiar and longstanding tradition holds that there is a special category of indexical thoughts-also known as de se, self-locating, first-person, or egocentric thoughts - that are necessary for intentional action. On such essentalist views indexical thinking is an irreducible feature of agency. ${ }^{1}$ Yet despite this consensus a number of philosophers have argued for various versions of anti-essentialism about indexicality. ${ }^{2}$ According to this opposition, there is no special class of indexical

\footnotetext{
1 Proponents of this view, or close relatives of it, include Castañeda (1966, 1975), Perry (1993 [1979]), Evans (1982), McGinn (1983), Kapitan (1995), Velleman (1996), Burge (2004), Owens (2011), Prosser (2015) and Babb (2016).

2 Anti-essentialists include Stalnaker (1999 [1981]), Millikan (1990), Devitt (2013), Douven (2013), Cappelen and Dever (2013) and Magidor (2015).
}

Andreas Stokke

andreas.stokke@ filosofi.uu.se

1 Swedish Collegium for Advanced Study, Department of Philosophy, Uppsala University, Box 627, 75126 Uppsala, Sweden 
thought, and correspondingly, the view that indexical thinking is essential for intentional action is misguided.

This paper defends a moderate form of essentialism. I argue that there is a significant category of intentional action that necessarily requires indexical thought. This kind of action is what I will call navigation. By navigation I mean, roughly, intentionally finding one's way from one place to another by using a certain kind of information about the world.

You might be given directions like "The library is on High Street, two blocks north of Elm Street." You might read a description of how to drive from Berlin to Hamburg. You might consult a map of a museum to find the section with Roman sculpture. I argue that intentionally using this kind of information to find one's way necessarily requires thoughts like "I'm on Elm Street now," "The Roman sculpture section is one floor up from here," or "We're approaching the A24 intersection."3

The claim that using this kind of information to find one's way requires indexical thoughts is not new. It has been suggested by essentialists such as Perry (1993 [1977], 1993 [1979]), Lewis (1979), Evans (1982), van Fraassen (2008), and others. My aim here is two-fold. First, I want to spell out a version of this idea that is neutral on some further essentialist claims. Second, I argue that anti-essentialists face a challenge in accounting for this kind of action without acknowledging the involvement of indexical thought or something equivalent.

If my argument is right, there are strong reasons to believe that there is a category of intentional action that necessarily requires indexical thought. This will be a substantial albeit moderate essentialist conclusion. It will be substantial because navigation is a central and pervasive category of action performed by the kind of agents we are. It will be moderate because it will be neutral on two strong essentialist claims. First, it will be neutral on the claim that there is a special kind of indexical thoughts that defy treatment by standard theories of propositional attitudes. Second, it will be neutral on the claim that any kind of intentional action necessarily requires indexical thought.

Section 2 introduces the opposition between essentialism and anti-essentialism, and I spell out the version of moderate essentialism to be defended here. Section 3 provides a way of understanding navigation and the involvement of indexical thought. In Sect. 4 I consider two anti-essentialist positions and show that both of them are forced to accept that navigation involves indexical thought or something equivalent. Finally, Sect. 5 brings out some general consequences of this conclusion.

\footnotetext{
3 For the purpose of this discussion, I group demonstratives like that and this under the heading of "indexicals," even though, familiarly, there is much to be said about the linguistic differences between demonstratives and other expressions often called "indexicals," such as, the personal pronouns or the locative indexicals, like here and there, and the temporal indexicals like now and today.
} 


\section{Essentialism and Anti-essentialism}

\subsection{Two Essentialist Claims}

It is useful to begin by recalling Perry's (1993 [1979]) classic example of the messy shopper:

I once followed a trail of sugar on a supermarket floor, pushing my cart down the aisle on one side of a tall counter and back the aisle on the other, seeking the shopper with the torn sack to tell him he was making a mess. With each trip around the counter, the trail became thicker. But I seemed unable to catch up. Finally it dawned on me. I was the shopper I was trying to catch. [...] I believed at the outset that the shopper with a torn sack was making a mess. And I was right. But I didn't believe that I was making a mess. That seems to be something I came to believe. And when I came to believe that, I stopped following the trail around the counter, and rearranged the torn sack in my cart. My change in beliefs seems to explain my change in behavior. (Perry 1993 [1979], 33)

In remarking on the shopper case, Perry emphasizes "the importance of the word "I" in my expression of what I came to believe." (loc. cit.) He argues that attributions involving other co-referring terms do not account for his action, and furthermore do not attribute the same belief:

When we replace it with other designations of me, we no longer have an explanation of my behavior and so, it seems, no longer an attribution of the same belief. It seems to be an essential indexical. (loc. cit.)

This passage highlights two essentialist tenets. The first of these can be stated as in E1.

E1 There are indexical propositional attitudes that cannot be accounted for by standard theories of propositional attitudes.

According to E1, there is something substantially different about the very attitudes involved in believing, for example, "I'm making a mess," as opposed to believing "John Perry is making a mess," even when "I" and "John Perry" co-refer. 4

Defenders of E1 differ on the nature of indexical thoughts. A lot depends on what one takes to be "standard theories of propositional attitudes." One way is to think of the orthodoxy that is being rejected as the view that attitudes like belief are nothing more than relations between subjects and classical propositions the truth-values

\footnotetext{
${ }^{4}$ Proponents of E1, in various guises, include Castañeda (1966), Perry (1993 [1977], 1993 [1979]), Lewis (1979), Chierchia (1989), Ninan (2013, 2016) Weber (2014), Stalnaker (2016), García-Carpintero (2017) and Torre (2017).
} 
of which vary with possible worlds and nothing else. ${ }^{5}$ Consequently, someone who holds that thoughts like "I'm making a mess" involve more than such a relation can be seen as an essentialist in the sense of E1.

In this paper I am interested in another kind of essentialist view also brought out by Perry's remarks on the shopper case. This is the view that indexical thinking is intimately bound up with intentional action. We might spell out this idea simply as in $\mathrm{E} 2$.

E2 Intentional action necessarily involves indexical thoughts.

There are different ways both of construing the locus of indexicality with respect to intentional action and of motivating its essentiality. An orthodox approach defends E2 on the basis that the type of intentions involved in intentional action must have an indexical element to them. ${ }^{6}$ Intentions of this kind are typically seen as the outputs of practical deliberation. ${ }^{7}$ According to this kind of essentialism, such an intention must be an intention that is characteristically about oneself if it is to lead to action. It must be an intention like "I intend myself to go shopping," or something equivalent.

By contrast, this paper focuses on the involvement of indexical thoughts in using information about a spatial region to find one's way. As I explain below, the version of this claim to be defended here is neutral on both E1 and E2.

\subsection{Moderate Essentialism}

Most proponents of E2 defend it in combination with some version of E1. Essentialists typically think that indexical thoughts present a challenge for classic theories of attitudes, and that those thoughts are moreover intimately tied up with intentional action. Yet it is important to note that E1 and E2 are independent. One can consistently deny E1 while endorsing E2. One might think that the simple relational picture of attitudes must be given up for reasons independent of issues concerning indexical thoughts, while still thinking that such thoughts are essential for agency.

Some anti-essentialists are explicit about the independence of these two essentialist ideas. For example, here is how Magidor (2015) describes the view that we have called E1:

There is a special class of propositional (or 'propositional-like') attitudes. These are self-locating or de se attitudes, ones that are typically expressed using indexical expressions such as ' $\mathrm{I}$ ' and 'now' [...]. Moreover, such attitudes pose a special challenge for our account of propositional attitudes. (Magidor 2015, 249)

\footnotetext{
5 Stalnaker (1999 [1981], 133-134) took Perry's radicalism to lie in his rejection of the simple relational view of propositional attitudes.

6 See e.g. Castañeda (1975), Kapitan (1995), Velleman (1996), Burge (2004) and Babb (2016).

7 Owens (2011) defends a view on which this kind of deliberation itself involves a first-person element.
} 
Magidor rejects this view, that is, E1. Further, she points out that doing so is compatible with accepting that indexical or de se attitudes are necessarily tied up with intentional action, that is, E2: ${ }^{8}$

One could plausibly argue that any account of ordinary propositional attitudes would need to involve modes of presentation (or similar devices), due to Frege's puzzle. One could then concede that there is one (or one kind of) mode that is first-personal, and that this mode is particularly important for attitudes that play a role in intentional action. However, this in itself does not require any revision of our standard account of attitudes or attitude ascriptions. (Magidor 2015, 258)

Magidor ultimately also rejects E2, or at least a strong reading of E2: "it is not even clear that first-personal beliefs are in fact essential to account for one's intentional actions-at least not in order to account for any action." (Magidor 2015, 259)

What I want to highlight is that, as Magidor points out, one can accept E2, the claim that intentional action requires indexical thought, without thereby also accepting E1, the claim that such thoughts constitute a special category that mandate a revision of standard theories of attitudes. Indeed, many will think that we should agree that standard Frege puzzles already motivate a departure from the simple relational view of attitudes. Yet recognizing this is consistent with accepting that cases like the shopper example, at least partly, motivate E2. Still, it might be held that this does not show that the kind of thoughts involved mandate a departure from orthodoxy about propositional attitudes.

Given this independence, I will remain neutral on E1 in what follows. My aim is to argue for a weaker version of E2:

E3 Some types of intentional action necessarily involve indexical thought.

I will argue for E3 by defending the claim that

E4 Navigation necessarily involves indexical thought.

If E4 is right, it will be a vindication of a moderate kind of essentialism. In particular, it will be a vindication of E3 that is neutral on both E1 and E2.

I will say more about the independence of E3 and E4 from E1 and the kind of moderate essentialism represented by the former theses later (see Sect. 4.4). In the next section I spell out the notion of navigation in more detail.

${ }^{8}$ Cf. Ninan $(2016,87)$. 


\section{Navigation}

\subsection{Perry and van Fraassen on Guide Books and Maps}

Another of Perry's (1993 [1979]) examples involved finding one's way by using a description of a route taken from a guidebook:

The author of the book Hiker's Guide to the Desolation Wilderness stands in the wilderness beside Gilmore Lake, looking at the Mt. Tallac trail as it leaves the lake and climbs the mountain. He desires to leave the wilderness. He believes that the best way out from Gilmore Lake is to follow the Mt. Tallac trail up the mountain to Cathedral Peaks trail, on to the Floating Island trail, emerging at Spring Creek Tract Road. But he does not move. He is lost. [...] Then he begins to move along the Mt. Tallac trail. If asked, he would have explained the crucial change in his beliefs this way: "I came to believe that this is the Mt. Tallac trail and that is Gilmore Lake." [...] These indexicals are essential, in that replacement of them by other terms destroys the force of the explanation, or at least requires certain assumptions to be made to preserve it. (Perry 1993 [1979], 34-35)

So Perry thinks that finding one's way by using a description of directions requires thoughts like "That's Gilmore Lake." Moreover, as this example illustrates, the relevant description might originally be made by the subject herself, and later recalled from memory or by reading. (We return to this later.)

Similarly, van Fraassen $(2008,78)$ argues that to use a map one needs "a judgment to the effect "I am now here on the map".," He writes,

This act of self-description too can be described and the information can be included on a bigger map (with the label "location of vF's map-reading at time $\left.t^{\prime \prime}\right)$. But then what I need to use this new map is still a self-ascription of location with respect to it. [...] With this new map, I can go on to self-ascribe a location by the different words "I am vF and it is now t". An attempt to replace or eliminate these self-ascriptions leads to an infinite regress, using an infinite series of maps. But even given the accuracy of the whole infinite series of maps, the regress does not succeed in eliminating the need for self-ascription. (van Fraassen 2008, 78-79)

As this illustrates, both Perry and van Fraassen accept E4, that is, the claim that intentionally moving from one location to another by using information about one's surroundings in the form of maps or directions necessarily requires indexical thought.

\footnotetext{
${ }^{9}$ van Fraassen $(2008,80)$ traces this claim to Kant $(1992[1768])$.
} 


\subsection{Evans on Egocentric and Objective Space}

How more precisely should we understand the involvement of indexical thought in using maps or directions in the way highlighted by Perry and van Fraassen? In an often quoted passage Evans (1982) wrote,

The subject conceives himself to be in the centre of a space (at its point of origin), with its co-ordinates given by the concepts 'up' and 'down', 'left' and 'right', and 'in front' and 'behind'. We may call this egocentric space, and we may call thinking about spatial positions in this framework centring on the subject's body 'thinking egocentrically about space'. (Evans 1982 154)

It is common to distinguish between this kind of egocentric conception of space and an "objective" conception of space. As Campbell $(1994,6)$ describes it, this is "the distinction between thinking about space from a particular point of view, as a subject at the center of one's world, and thinking about space independently of any particular viewpoint on it, in an impersonal way." Similarly, for Evans, objective space is characterized by non-indexical thinking:

Each place is represented in the same way as every other; we are not forced, in expressing such thinking, to introduce any 'here' or 'there'. (Evans 1982, 152)

Given this, one way of understanding E4 is as claiming that navigation necessarily requires translating from objective to egocentric space. This is a natural way of understanding van Fraassen's remarks on using maps. Similarly, Perry's hiker has an objective conception of the route out from Gilmore Lake, one that is not couched in egocentric terms. According to Perry, what the hiker needs is an indexical thought like, "That is Gilmore Lake," which makes Gilmore Lake a point that relates the objective conception of the spatial region he is in to his egocentric conception of space.

However, some think that any objective conception of space, in general, depends on an ability to translate between it and egocentric space. For instance, Evans held that

[A]ny subject who is able to think 'objectively' about space - any subject who can be credited with a cognitive map of any region - must know what is involved [...] in imposing his knowledge of the objective spatial relations of things upon an egocentric space. (Evans 1982, 162)

As Campbell $(1994,7)$ notes, a general motivation for this kind of asymmetric view is the thought that "all ways of representing space must be explicable in terms of their connections with perception and action, in terms of their relations to egocentric space."

By contrast, some anti-essentialists hold that we only ever have an objective conception of space, or at least any egocentric representation is only minimally so. That is, the only kind of egocentrism involved arises from the fact that some 
of the information available to an agent de facto concerns her own surroundings and her relation to them. On such a view there is no substantial sense in which egocentric information is used for action. For example, Cappelen and Dever (2013) write,

We think that contents are, and are used as, tools for representing (and, of course, sometimes misrepresenting) the objective state of the world. Some of the states represented are "perspectival" in the minimal sense that they are facts about our immediate environment, or facts about how things are in relation to us. Some of our representational systems are indexical in the minimal (Kaplanian) sense that they represent as they do in part in virtue of where they are situated in the world. But there's nothing more to the phenomenon than that-fundamentally, all information is objective information, and is used indifferently by us as such. (Cappelen and Dever 2013, 173)

Given this, we cannot argue for E4 by assuming a view according to which an objective conception of space depends on an ability to translate such a conception into an egocentric conception. In particular, we cannot assume such a view, given that, as Campbell brings out, it is commonly motivated by the thought that unless the subject can translate from objective to egocentric space, her spatial representations will be inert with respect to action.

\subsection{Public Information and Indexical Location}

Whatever one thinks of the general issue of the relation between the egocentric and objective conceptions of space, it is undeniable that we often use information that is not related to our egocentric space for navigation, as when using a map or directions. As a general label, let us call such information public information. ${ }^{10}$

It is public information that Wall Street is south of Central Park, that Edinburgh and Moscow are $2.510 \mathrm{~km}$ apart on the same latitude, or, in Perry's example, that following the Mt. Tallac trail is a way out from Gilmore Lake. This kind of public information is accessible to anyone who can competently read a map, a description, a set of directions, and the like. As in Perry's lost hiker case, public information, in this sense, may have been originally gathered by oneself and later recalled by memory or by some other means, such as being told or by reading.

To further clarify the notion of public information, note that much public information is standard de re information. For instance, the information that Wall Street is south of Central Park is de re information about those two places. Its truth-conditions depend rigidly on how things are with those places. What makes it public is that it is not related to anyone's egocentric space.

It should be common ground between anti-essentialists and essentialists that we use public information for navigation. Essentialists and anti-essentialists may

\footnotetext{
${ }^{10}$ Cf. Evans $(1982,162)$ who uses the terminology of "public space" similarly to his use of "objective space."
} 
disagree about whether thinking about the world in such terms ultimately depends on an egocentric conception of space. And they may disagree about whether we need to think of agents as ever using anything else than public information for navigation. Yet both sides should accept that one kind of action we routinely perform is to intentionally move from one location to another by using public information about the world.

Given this, a non-question-begging way of understanding E4 is as the claim that using public information for navigation necessarily requires indexical thought. To make this precise, one option is to follow Evans $(1982,162)$ in stating this in terms of thoughts of the form $\pi=p$, where $p$ is a referential term in the vocabulary of the relevant public information, such as "Gilmore Lake," "143 Main Street," or "55.754093N, 37.620407E," and $\pi$ is a referential term in indexical vocabulary, such as "here," "that place over there," or "the place where I am now". Hence, instances of $\pi=p$ are "That is Gilmore Lake," "The street I'm on now is Main Street," and so on.

Yet there are cases of navigation in which the subject is not in a position to think in terms of an identity of this kind. ${ }^{11}$ Suppose you are trying to find the Roman sculpture section of a museum. You ask someone where it is, and they tell you, "It's one floor up from here." So you go one floor up and find the Roman sculpture section. You navigated to the Roman sculpture section by using indexical information. But it would not be right to say that you were relying on a thought of the form $\pi=p$. Rather, what you relied on was an instance of predicating "one floor up from here" of the Roman sculpture section. Analogously, a thought like "Tasmania is south of here" involves predicating "south of here" of Tasmania.

A better suggestion is to understand the involvement of indexical thought in using public information in terms of the navigator being able to think of a location in two ways. We can spell this out as follows:

\section{Indexical Location Requirement (ILR)}

Necessarily, navigation is successful only if there is a location $l$ such that the navigator thinks of $l$ as both $\pi$ and $p$.

As above, $\pi$ and $p$ in ILR are referential terms. The reason for making this specification is to screen off a range of cases that are not instances of navigation in the sense I am interested in. Here is an example. You visit a castle and you take a walk in the garden. After a while you realize you have wandered into the famous garden maze. You remember that this maze is of the simple kind that one can escape by placing one hand on a wall and keep following it. So you make it to the exit.

This is not an instance of the kind of navigation involved in ordinary situations of using a map or directions to find one's way, or even more unusual scenarios like Perry's lost hiker case. Here is another example. You are in a small town. You want to find a particular blue house that you have been given a detailed description of. But you do not know where you are in the town, and there are no street signs to consult, no passersby to ask, or anything else that might help. So

11 Thanks to Hana Möller Kalpak for making this point to me. 
you check all the streets one by one making sure not to miss any. Eventually you find the house. Finding the blue house by this method is clearly not a case of navigation. Yet there is no relevant difference between this and the maze case.

To be sure, in both cases, you are arguably relying on some indexical information. In the maze case you are relying on a thought like, "I'm in the maze," and in the example of finding the blue house you are relying on something like, "I'm in the town with the blue house." Absent thoughts of this kind, you would not have escaped the maze or found the blue house. Correspondingly, there is a sense in which, in both cases, you think of a particular location both in an indexical and in a public way. For instance, in the maze case there is a location that you think of both as, say, "where I am" and "somewhere in the maze," namely, your own location. And analogously for the case of finding the blue house.

However, in situations of this kind one is merely relying on public information to think of the relevant location in question in a general way, such as "somewhere in the maze" or "somewhere in the town with the blue house." Instead, ILR is intended as a claim about cases in which one thinks referentially of a particular location both in indexical and public terms. Using maps provides an easy way of understanding this. What we are interested in are situations in which the navigator thinks of a particular location both in indexical terms and in non-indexical terms. Yet we are ruling out cases where the latter merely amounts to thinking of the relevant location in general terms, such as "somewhere on the map."

I want to comment on another type of case to help delineate the kind of action that is at stake here. Imagine that you have an app on your phone that displays the streets of a town and the people on the streets in real time. You can use a set of arrows to make one of the people walk, turn, stop, and so on. You have been told that this minion of yours is called "Judy." You are given the instruction: "Make Judy go one block north." Easy. You tap the arrows and Judy ends up one block north of where she was. However, what you did not realize is that you are Judy. So absorbed in your screen were you that you did not notice that you were the one who ended up one block north.

At first sight, it might be thought that, in this case, you navigated one block north without having the kind of indexical thought involved in ILR. However, the kind of action you performed in this case is not the same kind of action as one performs when one uses a map to navigate. (We return to this in Sect. 4.4.) In the Judy case the action you performed is naturally described as being moved one block north by someone. The person who moved you happened to be yourself. But this is not essential to the example. Parallel cases in which someone else has control over you, or in which you have control over someone else, are not relevantly different. Yet such cases are different from navigation cases. The latter are cases that are most naturally described as moving to some location, rather than being moved to some location by someone (perhaps yourself).

As this suggests, the difference is that, in the Judy case, you did not intentionally move one block north, although you intentionally moved someone (who happens to be you) one block north. By contrast, navigation, as we have understood it here, involves intentionally moving from one location to another. 
A final remark on ILR is in order. ILR is merely a necessary condition. One reason for this is the obvious one that, since we are thinking of navigation as intentional action, the agent also needs a suitable intention. Another reason, more relevant here, is that, even if the right intention and all other conditions are in place, navigation also requires having an orientation. Roughly, an orientation is a correlation of egocentric notions like "forward," "backward," "left," "right," "up," and "down" with locations or directions in public terms. ${ }^{12}$ For example, one can (at least partially) orient oneself by coming to think, "Main Street is behind me," "The Roman sculpture section is up from here," or "North is that way."

Having an orientation, in this sense, is arguably not necessary for being able to think the kind of thought foregrounded by ILR. That is, thinking of a location in both public and egocentric terms may enable you to locate yourself with respect to a map even if you lack orientation. For instance, you might come to think, "I'm on Main Street" even if you have no way of correlating egocentric notions like "forward," "backward," "right," and "left," with north, south, east, and west on the map. At the same time, one might think that having a conception of "forward," "backward," "right," "left," and so on is a necessary component of having an egocentric conception of space at all. ${ }^{13}$ Indeed, this was suggested by the passage from Evans $(1982,154)$ we quoted above. But even if this turns out to be right, there is still a further issue concerning the involvement of orientation in navigation. To focus the discussion on ILR, however, I will set aside orientation and only focus on location in what follows. ${ }^{14}$

In the next section I consider two anti-essentialist proposals and argue that none of them can avoid accepting ILR or some equivalent claim. These are, first, the view defended by Millikan (1990), and second, the strong anti-essentialism of Cappelen and Dever (2013). I take each of these two versions of anti-essentialism to be in a good position to reject ILR, given their focus and strategies. Accordingly, if it can be argued that these views will not be able to reject ILR (or some equivalent thesis) after all, this will be a good reason to think that anti-essentialists are unable to account for navigation. Needless to say, we cannot rule out that other anti-essentialist proposals can be developed that may answer the challenge. However, if my argument is right, at least we will have shown that anti-essentialists, as things stand, need to work out an account of navigation that does not (perhaps implicitly) endorse a principle like ILR.

\footnotetext{
12 See van Fraassen (2008, 79-80).

13 Thanks to an anonymous reviewer for suggesting this.

14 A further issue here concerns the question of whether space itself is oriented or objective. On this, see e.g. Lee (2006), Baker (2012), and the essays in Van Cleve and Frederick (1991).
} 


\section{Navigation and Anti-essentialism}

\subsection{A Toy Example}

Imagine that Ahab is visiting an unfamiliar town. He wants to get to High Street to meet his friend. He is on Main Street. But Ahab does not know which street he is on. To help Ahab find his way, his friend has drawn for him the map below.

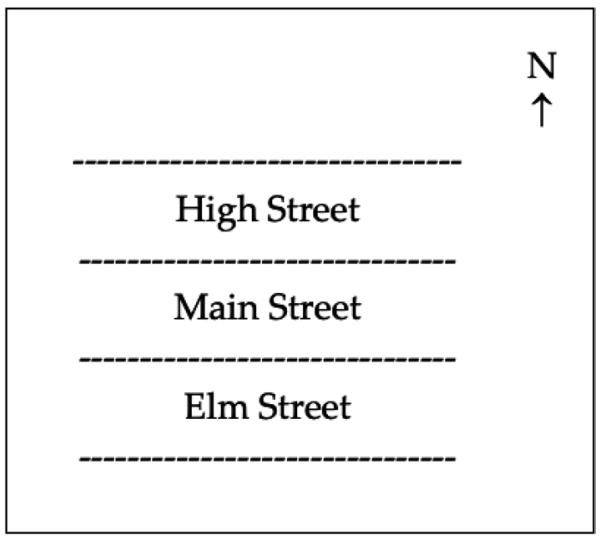

The map shows that High Street is one block north of Main Street, and that Main Street is one block north of Elm Street. We assume that Ahab knows this from having competently read the map. Yet it is not essential that Ahab acquires this information via the map rather than in some other way, such as having been told orally or in writing, or by some other means. Perhaps Ahab has himself drawn the map earlier or memorized the relevant information from having explored the town in the past. But for simplicity we will continue to speak in terms of Ahab using the map to navigate. We assume that Ahab is oriented, so he knows which way is north and which way is south. (If you like, imagine that he is equipped with a reliable compass.)

Further, analogously to what we said earlier, finding High Street by randomly walking around until he sees his friend, or first going all the way to the north and then all the way to the south looking for her, and so on, are not cases of navigation in our sense. The claim cashed out by ILR is that to use the information encoded in the map to intentionally find his way to High Street, Ahab needs an indexical thought.

Correspondingly, to falsify ILR, our opponent needs to argue that Ahab could intentionally navigate from Main Street to High Street even if there is no location that he thinks of as both $\pi$ and $p$. In this case $\pi$ might be "the street I'm on now," "two blocks south of here," and so on. Instances of $p$ might be "High Street," "the street one block north of Elm Street," and so on. 


\subsection{Active Self Names}

One suggestion for the anti-essentialist is to follow Millikan (1990) in arguing that there is no reason to think that we employ indexicals in thought. Rather, Millikan claims that we can equally well think that we have inner names that play a special role in being intimately connected to our dispositions to act, desires, intentions, and so on. She calls such names active self names (henceforth, ASNs). Millikan writes,

Now it is trivial that if I am to react in a special and different way to the knowledge that I, RM, am positioned so in the world, a way quite unlike how I would react knowing anyone else was positioned so in the world, then my inner term for RM must bear a very special and unique relation to my dispositions to act. But what does that have to do with indexicality? My inner name "RM" obviously is not like other names in my mental vocabulary. It is a name that hooks up with my knowhows, with my abilities and dispositions to act, in a rather special way. [...] Let us call it @ "RM", or RM's "active self name". It names a person whom I know, under that name, how to manipulate directly; I know how to effect her behavior. But in order to know how to manipulate this person, why would I need to think indexical thoughts? (Millikan 1990, 730)

If there are no indexicals in thought, but only ASNs, the suggestion that navigation requires indexical thoughts is a forteriori false. Correspondingly, if the anti-essentialist can argue that navigation only requires thoughts in terms of ASNs, this will be a way of rejecting our claim that navigation requires indexical thoughts.

As described by Millikan, thoughts involving ASNs play an analogous role with respect to action to the kind of indexical thoughts discussed by essentialists. I want to highlight three aspects of this similarity here. First, ASNs are self-representations. ASNs are names that agents have for themselves. Second, ASNs are actionmotivating. ASNs account for the fact that, for instance, Ruth Millikan will "react in a special and different way to the knowledge that I, RM, am positioned so in the world, a way quite unlike how I would react knowing anyone else was positioned so in the world." (loc. cit.) Similarly, on this view, when John Perry learns " @JP is making a mess," this might prompt action that would not be prompted by him coming to know, say, "The shopper with the torn sack is making a mess," despite the coreference. Third, and relatedly, ASNs are operative in the sense that contents involving ASNs can effectuate action. As Millikan says, her ASN "names a person whom I know, under that name, how to manipulate directly." (loc. cit.)

Given this parallel between what we have been calling indexical thoughts and what Millikan describes as thoughts involving one's ASN, it is natural to think that Millikan's view is committed to a claim analogous to ILR. On Millikan's view navigation arguably requires that one think of a location both in public terms and in terms of one's ASN, as spelled out below: 


\section{Active Self Name Requirement (ASNR)}

Necessarily, navigation is successful only if there is a location $l$ such that the navigator thinks of $l$ as both $v$ and $p$.

Here " $v$ " is a referential term in the vocabulary of the navigator's ASN.

In terms of our example, given Millikan's view, for Ahab to use the information he has gathered from the map to intentionally find his way to High Street, he needs to come to think a thought like "@ Ahab is on Main Street," "High Street is one block north of where @Ahab is," or something similar. Even if Ahab has another way of representing himself, Millikan's view implies that one needs a thought involving one's ASN.

So, on this anti-essentialist view, even though navigation may not require an indexical thought in Perry's sense, it still requires a thought involving a self-representation that is action-motivating and operative. In Sect. 4.4 below I will argue that, in order to account for the kind of intentional action at stake here, one must further accept that thoughts involving this kind of self-representation are genuinely indexical or de se. Before turning to that, though, we should consider the option for the anti-essentialist of stopping short of accepting that action-motivating, operative self-representations are needed for action. A view of this kind has been suggested by Cappelen and Dever (2013). We turn to their account next.

\subsection{Action Inventories}

Defending a strong form of anti-essentialism, Cappelen and Dever challenge views like Millikan's by asking, "Why think that the agent has to represent herself at all [...]?" (Cappelen and Dever 2013, 45) Instead they argue that one can coherently think of action purely along third-person lines: ${ }^{15}$

Every agent has a very wide range of third-person beliefs and desires that give rise to third-person intentions, which in turn rationalize or motivate actions (via their recognition). Not all of these intentions are going to produce action, at least in normal cases (perhaps in a god they would). This is because a given agent has an "action inventory": a range of actions that he can perform. An agent constantly seeks to match his intentions with his action inventory, and when he finds a match, action occurs. When there's no match, the intention idles, and doesn't motivate or rationalize action. (Cappelen and Dever 2013, 50)

On this view we do not have to think that agents have action-motivating, operative self-representations. Instead, all that is needed is a list of desires, a list of beliefs, and an inventory of feasible actions.

For instance, suppose John Perry has the desire that John Perry buy sugar and the belief that John Perry can buy sugar at the store. If, moreover, buying sugar at the

\footnotetext{
15 Cappelen and Dever are not arguing for the actuality of this model of intentional action, but rather for its possibility, thus targeting the essentialist claim that first-person thoughts are necessary for intentional action.
} 
store is an action that John Perry can perform (it is on his inventory), this action will be triggered and John Perry buys sugar at the store. Yet we do not need to follow Millikan in assuming that John Perry has a thought involving some way of representing John Perry (himself) that is action-motivating and operative. However, as I will argue below, even on Cappelen and Dever's action inventory picture, to account for what happens in simple cases of navigation, one must accept that agents have action-motivating, operative self-representations. ${ }^{16}$

Consider how precisely this model will account for a case like Ahab's. Again, suppose that Ahab has the map and wants to get to High Street. Even though he is in fact on Main Street, he does not know where he is. Given the setup of the example, we assume that Ahab's desires include the desire labeled D1 below.

D1 Ahab gets to High Street.

Following Cappelen and Dever, we think of this as a purely third-person representation-it is just a desire about someone called "Ahab." Further, we also assume that Ahab's action inventory includes A1.

A1 Go one block north.

A1 is one of the things Ahab can do. Yet so far Ahab is inactive, since there are no beliefs to produce a "match," in Cappelen and Dever's sense. What is needed, on the one hand, are suitable beliefs corresponding to the information given by the map, and on the other hand, a belief about Ahab's current position.

As before, we assume that Ahab has available information that can be gathered from a competent reading of the map. In particular, we assume his beliefs include B1.

B1 One can get from Main Street to High Street by going one block north.

Supposing further that the belief list is closed under (reasonable) deduction, we can assume that B2 is also on the list.

B2 Ahab can get from Main Street to High Street by going one block north.

Again, B2 is a purely third-person belief. Yet, in order to trigger A1, Ahab also needs the belief in B3.

B3 Ahab is on Main Street.

If Ahab can acquire this belief, at least prima facie, it should in turn generate B4, which would produce a match with D1 to realize A1.

16 See Babb (2016) for a different kind of criticism of Cappelen and Dever concerning intentions to act. 
B4 Ahab can get to High Street by going one block north.

I take it to be clear that the belief that Ahab is on Main Street must arise due to some interaction with the environment, for example, by Ahab seeing a street sign, by him asking someone where he is, or something similar. There is no way for Ahab to deduce B3 from his other information, or in some other way coming to believe that Ahab is on Main Street without gathering information about Ahab's, that is, his, surroundings. ${ }^{17}$

Suppose that Ahab sees a street sign that says "Main Street." Cappelen and Dever should agree that Ahab can thereby acquire B3. They might do so by asking us to imagine that Ahab's perceptual faculties are wired so that seeing the street sign will produce B3, even though there is no point at which Ahab thinks something like "I'm on Main Street," or "I'm seeing that street sign," or the like. ${ }^{18}$ Again, Cappelen and Dever will think of B3 and B4 as purely third-personal.

Assume that Ahab acquires B3, perhaps by seeing a street sign, or in some other way. If so, he should also acquire B4. There should now be a match between B4 and D1, and A1 will be triggered. However, a crucial point to note is that, for Cappelen and Dever's model to work, an agent's system needs to be able to identify subjects on the belief list with subjects on the desire list. In our case the system needs to recognize that "Ahab" in D1 and "Ahab" in B4 co-refer. If it does not, clearly, there is no match, and no action will be produced. This is so even if we think of D1 and B4 as purely third-personal.

In particular, Ahab might receive information about another person called "Ahab," and will need to be able to distinguish this referent of "Ahab" from, for example, the referent of "Ahab" in D1 and B4. If not, this will be no different from, for example, having the belief that Ishmael can get to High Street by going one block north and the desire that Starbuck gets to High Street.

We might propose that the system is set up so that it will distinguish referents of names and other referential expressions depending on the other information it has. If so, the items on its belief and desire lists are, at least sometimes, fully disambiguated. So we might think, for example, that typically the system is able to distinguish between referents upon hearing things like, "You are on Main Street" as opposed to, for example, "Ahab is behind you." So, for instance, it might be proposed that these two kinds of received information will generate two third-person beliefs like "Ahab is on Main Street" and "Ahab ${ }_{2}$ is behind Ahab $_{1}$ "

\footnotetext{
17 To be sure, he could take a guess and by luck acquire a true belief about Ahab's location. I assume it is clear that this and other similar possibilities are irrelevant to what is at stake here.

18 Perhaps it can be argued that Cappelen and Dever can only allow that Ahab may gain information like "Someone is on Main Street" from perception. (Thanks to an anonymous reviewer for suggesting this.) If so, their anti-essentialism is in a weaker position than the one I am assuming here. On the other hand, there is arguably no logical obstacle to supposing that, crudely, each agent $x$ is built such that when $x$ 's perceptual faculties observes a street sign saying "Main Street," this will produce the belief in $x$ that $x$ is on Main Street. Something similar might be claimed for cases in which, for instance, $x$ is told "You are on Main Street," and so on.
} 
Suppose we specify that D1 and B4 are successfully disambiguated in this way, as in $\mathrm{D} 1 *$ and $\mathrm{B} 4 *$.

D1* Ahab ${ }_{1}$ gets to High Street.

B4* Ahab ${ }_{1}$ can get to High Street by going one block north.

Yet securing co-reference is not enough. Crucially, the system will moreover need to be set up in such a way that beliefs and desires about Ahab ${ }_{1}$, and not $\mathrm{Ahab}_{2}$, let alone someone else, such as Ishmael ${ }_{7}$ or Starbuck $_{3}$, are those that lead to action. Unless the system recognizes that the action inventory is to be brought into play only once there is a match between a belief and a desire of which $\mathrm{Ahab}_{1}$, and not someone else, is the subject, it will be ineffectual.

This, however, is just a way of presupposing a representation that plays the central role in action, like indexicals or Millikanian ASNs. In terms of our example, "Ahab ${ }_{1}$ " is not relevantly different from a Millikanian ASN like "@ Ahab." In other words, Cappelen and Dever's anti-essentialism collapses into Millikan's. That is, both versions of anti-essentialism must accept that agents have action-motivating, operative self-representations.

To be sure, Cappelen and Dever's view is arguably compatible with denying that the relevant representation of the agent should be construed as a name. Instead, they might insist that action can be understood in terms of some other way of representing the agent. Yet this does not constitute a substantial difference from Millikan's view, given that, as the Ahab case shows, navigation requires some action-motivating, operative representation of the agent.

\subsection{Self-Representation de re and de se}

So far I have argued that anti-essentialists like Millikan and Cappelen and Dever must accept that navigation requires that the agent has a way of representing herself that is tied to action in the way that essentialists take indexical thoughts to be tied to action, in the sense of being action-motivating and operative. Yet for all we have said, the kind of self-representation involved might be a Perry style indexical, a Millikanian ASN, a disambiguated representation privileged by an action inventory along the lines of Cappelen and Dever, or something else. As I suggested, anti-essentialists might not subscribe to the letter of ILR. For instance, Millikan might endorse a thesis like ASNR instead. We can imagine similar theses that Cappelen and Dever might adopt.

To further vindicate the kind of moderate essentialism I am defending here, we need to argue that the relevant thoughts involved in navigation should be understood as the kind of first-person or de se thoughts championed by essentialists who defend E2. Indeed, one might think that all our toy example brings out is that Ahab needs to be able to think de re about himself in a way that is action-motivating and operative. But, one might ask, how is this a vindication of $\mathrm{E} 4$, the moderate essentialist thesis that navigation requires indexical or de se thoughts?

One way of motivating this challenge is to note that, as described by Millikan, even though ASNs are eo ipso self-representations, there is nothing inherently firstperson, or de se about ASNs. As Millikan says, her ASN is just a name that "names a person whom I know, under that name, how to manipulate directly; I know how to 
effect her behavior." (Millikan 1990, 730) Given this, there is no obstacle in principle to imagining that one might have active names for someone other than oneself.

For instance, we can imagine a scenario in which Ahab is able to think about another agent, say Starbuck, in such a way that when Ahab thinks, "@ Starbuck, go one block north!" Starbuck goes one block north. This makes the active name "@Starbuck" operative. We can further imagine that "@Starbuck" is action-motivating. For instance, suppose that if Ahab learns "@Starbuck is about to be hit by a bus," this will motivate Ahab to think “@Starbuck, get out of the way!" or something similar.

One might think that, in this kind of case, navigation is possible purely in terms of this active name for someone else. For instance, suppose this Ahab has the desire “@Starbuck gets to High Street” and the belief “@Starbuck can get to High Street from Main Street by going one block north.” If Ahab can come to think “@Starbuck is on Main Street," this will make him think, "@Starbuck, go one block north!"

However, even if we grant the possibility of active names for agents other than oneself, this kind of case is not an instance of the phenomenon under discussion here. That is, this kind of case is not an example of the everyday action of intentionally moving from one place to another by using public information about one's surroundings. Rather, in this case Ahab uses public information to figure out how to fulfil the desire that Starbuck gets to High Street, and as a result intentionally makes Starbuck go one block north. It is plausible that such an action requires that one think of some location both in public terms and in terms of the relevant active name. But there is no sense in which this kind of case can be described as an instance of navigation. In our example Ahab did not navigate to High Street, and nor did Starbuck.

The same observations apply, mutatis mutandis, to cases in which the agent one controls by an action-motivating, operative de re representation is oneself, as in the case of ASNs or "Ahab ${ }_{1}$ " in the example above. Consider again the phone app that allows you to make Judy go down the street, turn, stop, and so on (see 3.3). For example, you can make Judy go one block north. What you do not realize is that you are Judy. So you are the one who ends up one block north. As we said, in this case you did not intentionally move one block north, but rather you intentionally moved someone (who happens to be yourself) one block north.

To be sure, it is true to say that, in the Judy case, you moved one block north. But it is clearly not true to say that you intentionally moved one block north. Even though it is true that you intentionally moved someone (yourself) one block north. In other words, in this case (i) is false while (ii) is true. ${ }^{19}$

(i) You intentionally moved one block north.

(ii) You intentionally moved someone (yourself) one block north.

\footnotetext{
${ }^{19}$ Note that this difference remains if one substitutes "Judy" for "you" and "herself" for "yourself" in (i)-(ii), and hence has nothing to do with the use of the indexical pronoun in the descriptions of the example.
} 
The difference between this case and a case in which (i) is true is clear. Namely, to intentionally move one block north, you need to think about the agent whose actions you control as yourself. That is, you need an indexical or de se self-representation. The representation you have of Judy (yourself) in this case, the view of Judy on the screen, is analogous to an action-motivating, operative de re self-representation, such as a Millikanian ASN. Hence, the Judy case provides a reason to think that, unless such de re self-representations constitute a way of thinking about oneself as oneself, they will not be able to provide an account of the category of intentional action at stake here.

Similarly, imagine a version of Ahab who is able to think de re about an agent, Ahab, in such a way that when Ahab thinks, "@Ahab, go one block north!" Ahab goes one block north. Yet Ahab does not realize that he is the referent of "@Ahab." If this Ahab comes to think, “@Ahab is on Main Street," he might match this with his desire "@Ahab gets to High Street," and this might prompt the thought, “@Ahab, go one block north!" The result is that he ends up one block north. However, again, in this case it is false that Ahab intentionally went one block north, even though it is true that he intentionally made Ahab (himself) go one block north. As in the Judy case, it is clear that the difference is that, for Ahab to intentionally go one block north, Ahab must have a de se representation of himself.

As this suggests, navigation requires an action-motivating, operative de se selfrepresentation. And moreover, navigation requires that there be a location that one thinks of both in a public vocabulary and in terms of this kind of de se self-representation. In the case just described Ahab did not navigate to High Street, even though he used public information to move Ahab (himself) to High Street. Yet we should concede that the relevant self-representation need not be understood as an indexical pronoun. It might be an ASN or something else, for all we have said. Indeed, one can arguably have ways of thinking about oneself that are not correctly understood on the model of either names or indexical pronouns. Even so, the relevant thoughts need to be de se in the sense that they need to involve representing oneself as oneself, rather than as someone else, as in the Judy case. (For convenience, I will continue to use the label "indexical" in what follows.)

It might be pointed out here that Cappelen and Dever explicitly describe their action inventory model in terms of intentions. As they say, "An agent constantly seeks to match his intentions with his action inventory, and when he finds a match, action occurs." (Cappelen and Dever 2013, 50) Yet we have described things as if the agent matches his beliefs and desires.

However, even if we think of the action inventory model in terms of intentions, the argument that agents need de se self-representations remains. Suppose that Ahab can form intentions about an agent, Ahab, such as the intention "@Ahab go one block north." Since going one block north is also an action that Ahab can perform, there is a match, and Ahab goes one block north. But again, if Ahab does not realize that he is the referent of "@Ahab," that is if "@ Ahab" is not a de se self-representation, it is still false that Ahab intentionally went one block north. What happened was that Ahab had an intention about someone (who happened to be himself) which resulted in that person going one block north. But Ahab did not have an intention to 
go one block north, and there is no sense in which he intentionally went one block north.

At this point anti-essentialists might respond by taking the cases of using a purely de re self-representation to relocate oneself by relying on public information to show that there is no special category of navigation, in the sense we have ben using this term. They might insist that all we need is to be able to describe cases such as the one where Ahab uses the de re representation "@Ahab" to move Ahab (himself) to High Street by way of coming to think "@Ahab is on Main Street." One can see this as a choice point between taking navigation to be a substantial category or not. I have taken the former position. But, moreover, it is fair to say that if one wants to take the latter standpoint, one will need to explain the at least prima facie difference between descriptions like (i) and (ii) for the relevant cases.

At the same time, the conclusion argued for here is moderate in the sense that, while we may have established that navigation requires action-motivating, operative indexical thoughts, we have not tried to establish that such thoughts satisfy E1. As we saw earlier (in Sect. 2.2), it is important to distinguish the essentialist claim that indexical thoughts play a special role with respect to (some) intentional action from the claim that such thoughts constitute a special category that mandates a departure from orthodox theories of attitudes.

Citing Magidor (2015), who we quoted earlier, Ninan (2016) puts the point as follows:

one should distinguish two claims [...]: (i) that de se attitudes have certain distinctive features that differentiate them from non-de se attitudes; and (ii) that $d e$ se attitudes raise a distinctive problem for theories of propositional attitudes. Even if the first point is granted, the second does not follow (though presumably the first follows from the second). (Ninan 2016, 87)

The claim I have argued for-that navigation necessarily involves indexical thought - is a version of the first of these. That is, one distinctive feature of indexical attitudes is that they are necessary for a central kind of intentional action, namely navigation. This result is neutral on whether such attitudes can ultimately be understood by theories of attitudes that we accept for reasons not having to do with indexicality, or the de se.

In the next section I expand more on the importance of navigation as a category of intentional action performed by agents like ourselves.

\section{The Importance of Navigation}

\subsection{Embodied Agents}

On the way we have understood this notion, to navigate is to intentionally move from one spatial location to another by using public information. Given this, navigation is possible only for what we can call embodied agents. In particular, say that an agent is embodied only if she is located somewhere in space. If an agent is not located anywhere in space, she cannot move from one spatial location to another. 
Consider the possibility of disembodied creatures-agents that are not located anywhere in space-capable of intentional action, such as the staple example of angels. Even though angels are capable of intentional action, given the way we are thinking of navigation, angels do not navigate. Since angels do not move from one spatial location to another, ipso facto they do not do so by using public information such as maps or guide books. In other words, on this way of understanding navigation, if ILR is right, indexical thinking is a necessary condition on a central kind of intentional action peculiar to embodied agents. We are embodied agents. So, if ILR is right, indexical thinking is a necessary condition on a central kind of intentional action peculiar to ourselves.

Yet it might be said that the suggestion that navigation necessarily requires embodiment is too narrow. For instance, it might be said that one can navigate purely in one's imagination. ${ }^{20}$ Clearly, you can imagine wanting to get to High Street but not knowing which street you are on. You can imagine that you have Ahab's map, and that upon seeing a street sign you come to think, "I'm on Main Street," and so you make your way one block north to High Street.

Did you navigate from Main Street to High Street in this case? There is a clear sense in which you did not. Rather, you imagined navigating from Main Street to High Street. Still, perhaps it can be argued that there is equally a sense in which this case and the non-imaginative case are sufficiently similar with respect to the interaction of indexical and public information, and correspondingly, interaction between egocentric and absolute conceptions of the relevant spatial region. Does this mean that navigation is not peculiar to embodied agents after all? Clearly, this depends on whether imagining things like what we described above is peculiar to embodied agents in the first place.

We cannot begin to approach these issues here. However, even if we should ultimately refrain from maintaining that navigation necessarily involves spatial movement, and hence refrain from maintaining that navigation is only possible for embodied agents, this does not weaken the main observation that navigation is a central and characteristic kind of intentional action performed by embodied agents like ourselves.

\subsection{Itinerant Agents}

Further, it is a feature of at least some forms of embodiment that one may find oneself in an environment that outstrips one's egocentric space. More particularly, depending on their world and their cognitive capacities, embodied agents may find that there are locations that they can think of only in what we have called public terms. To be sure, there are plausibly embodied agents, possible or actual, who live in a spatial environment that is never larger than what can at any time be thought of in egocentric terms. Such closely confined agents presumably do not need to navigate by using public information.

20 Thanks to an anonymous reviewer for suggesting this. 
Yet for many other embodied agents being bound to a particular spatial location means that their environment cannot be contained within their egocentric space. Instead, there are locations that they can think of only in public terms. Such agents are what we can call itinerant agents. There are locations that they can travel to only by (at least initially) thinking of them in terms that are not related to their egocentric points of origin. We ourselves are itinerant agents. We can think of remote places, like the far side of the moon, islands in another hemipshere, or the other side of town, but usually only in terms of public information.

If ILR is right, indexical thinking is a necessary condition on a central kind of intentional action performed by embodied, itinerant agents, such as ourselves. Any creature that is located somewhere in space and is capable of using what we have called public information about its spatial environment to intentionally relocate itself can do so only by relying on an instance of thinking about a particular location both in indexical and public terms.

Acknowledgements Open access funding provided by Uppsala University. I am grateful to Anandi Hatiangadi, Brian Ball, Hana Möller Kalpak, Ioannis Votsis, Jessica Pepp, Matti Eklund, Sten Lindström, Torfinn Huvenes, and two anonymous referees for valuable comments and discussion of this material. For financial support, I thank Riksbankens Jubileumsfond and the Swedish Collegium for Advanced Study.

Open Access This article is licensed under a Creative Commons Attribution 4.0 International License, which permits use, sharing, adaptation, distribution and reproduction in any medium or format, as long as you give appropriate credit to the original author(s) and the source, provide a link to the Creative Commons licence, and indicate if changes were made. The images or other third party material in this article are included in the article's Creative Commons licence, unless indicated otherwise in a credit line to the material. If material is not included in the article's Creative Commons licence and your intended use is not permitted by statutory regulation or exceeds the permitted use, you will need to obtain permission directly from the copyright holder. To view a copy of this licence, visit http://creativecommons.org/licen ses/by/4.0/.

\section{References}

Babb, M. (2016). The essential indexical of intentional action. The Philosophical Quarterly, 66(264), $439-457$.

Baker, D. (2012). The experience of left and right meets the physics of left and right. Noûs, 46(3), 483-498.

Burge, T. (2004). Memory and persons. Philosophical Review, 113, 289-337.

Campbell, J. (1994). Past, space, and self. Cambridge, MA: MIT Press.

Cappelen, H., \& Dever, J. (2013). The inessential indexical-On the philosophical insignificance of perspective and first person. Oxford, New York: Oxford University Press.

Castañeda, H.-N. (1966). 'He': A study in the logic of self-consciousness. Ratio, 8, 130-157.

Castañeda, H. N. (1975). Thinking and doing. Dordrecht: Reidel.

Chierchia, G. (1989). Anaphors and attitudes de se. In R. Bartsch, J. van Benthem, \& B. van Emde (Eds.), Semantics and contextual expression (pp. 1-31). Dordrecht: Foris.

Devitt, M. (2013). The myth of the problematic de se. In A. Capone \& N. Feit (Eds.), Attitudes de se: Linguistics, epistemology, metaphysics. Stanford: CSLI Publications.

Douven, I. (2013). The epistemology of de se beliefs. In A. Capone \& N. Feit (Eds.), Attitudes de se: Linguistics, epistemology, metaphysics. Stanford: CSLI Publications.

Evans, G. (1982). The varieties of reference (J. McDowell, Ed.). Oxford: Oxford University Press.

García-Carpintero, M. (2017). The philosophical significance of the de se. Inquiry, 60(3), 253-276. 
Kant, I. (1992 [1768]). Concerning the ultimate ground of the differentiation of directions in space. In D. Walford (Ed.), Immanuel Kant: Theoretical Philosophy (pp. 1755-1770). Cambridge: Cambridge University Press.

Kapitan, T. (1995). Intentions and self-referential content. Philosophical Papers, 24, 151-166.

Lee, G. (2006). The experience of left and right. In T. Gendler \& J. Hawthorne (Eds.), Perceptual experience. Oxford, New York: Oxford University Press.

Lewis, D. (1979). Attitudes de dicto and de se. Philosophical Review, 88, 513-43.

Magidor, O. (2015). The myth of the de se. Philosophical Perspectives, 29, 249-283.

McGinn, C. (1983). The subjective view: Secondary qualities and indexical thoughts. Oxford: Clarendon Press.

Millikan, R. (1990). The myth of the essential indexical. Noûs, 24(5), 723-734.

Ninan, D. (2013). Self-location and other-location. Philosophy and Phenomenological Research, 87(2), $301-331$.

Ninan, D. (2016). What is the problem of de se attitudes? In M. García-Carpintero \& S. Torre (Eds.), About oneself: de se thought and communication (pp. 86-120). Oxford, New York: Oxford University Press.

Owens, D. (2011). Deliberation and the first person. In A. Hatzimoysis (Ed.), Self-knowledge (pp. 261278). Oxford, New York: Oxford University Press.

Perry, J. (1993 [1977]). Frege on demonstratives. In The problem of the essential indexical and other essays (pp. 3-32). Oxford, New York: Oxford University Press.

Perry, J. (1993 [1979]). The problem of the essential indexical. In The problem of the essential indexical and other essays (pp. 3-52). Oxford, New York: Oxford University Press.

Prosser, S. (2015). Why are indexicals essential? Proceedings of the Aristotelian Society, 115(3), 211-233.

Stalnaker, R. (1999 [1981]). Indexical belief. In Context and content (pp. 130-149). Oxford, New York: Oxford University Press.

Stalnaker, R. (2016). Modeling a perspective on the world. In M. García-Carpintero \& S. Torre (Eds.), About oneself: de se thought and communication (pp. 121-140). Oxford, New York: Oxford University Press.

Torre, S. (2017). In defense of de se content. Philosophy and Phenomenological Research, 97(1), $172-189$.

Van Cleve, J., \& Frederick, R. (Eds.). (1991). The philosophy of right and left. Dordrecht: Kluwer.

van Fraassen, B. C. (2008). Scientific representation: Paradoxes of perspective. Oxford, New York: Oxford University Press.

Velleman, D. (1996). Self to self. Philosophical Review, 10, 539-76.

Weber, C. (2014). Indexical beliefs and communication: Against Stalnaker on self-location. Philosophy and Phenomenological Research, 90, 640-663.

Publisher's Note Springer Nature remains neutral with regard to jurisdictional claims in published maps and institutional affiliations. 